\title{
High Intensity vs Low Intensity COVID-19 Gymnastics to Increase Aerobic Capacity and Mental Toughness in Different Sex of Adult People
}

\author{
Komarudin Komarudin \\ Faculty of Sport and Health Education: Universitas \\ Pendidikan Indonesia \\ Bandung, West Java, Indonesia \\ komarudin_pko@upi.edu \\ Sandey Tantra Paramitha \\ Faculty of Sport and Health Education: Universitas \\ Pendidikan Indonesia \\ Bandung, West Java, Indonesia \\ sandeytantra18@upi.edu
}

\author{
Muhammad Gilang Ramadhan \\ Faculty of Sport and Health Education: Universitas \\ Pendidikan Indonesia \\ Bandung, West Java, Indonesia \\ gilangramadhan16@upi.edu \\ Geraldi Novian \\ Faculty of Sport and Health Education: Universitas \\ Pendidikan Indonesia \\ Bandung, West Java, Indonesia \\ geraldi.novian@upi.edu
}

\begin{abstract}
The COVID-19 outbreak has made changes in the process of social life, including sports activities. Individuals become limited in carrying out activities so that they often choose not to do physical activities. Individual inactivity causes various internal problems, such as fatigue and mental problems. The author creates an exercise that aims to overcome this problem by manipulating the intensity in it, namely COVID-19 gymnastics. This study aims to test the COVID-19 exercise with low and high intensity on increasing aerobic capacity and mental toughness in different sex of adult people. The experimental method for 6 weeks was carried out in this study to 150 subjects (65 men and 85 women) by professional gymnastics experts. The Walk Test and Mental Toughness Inventory were used as research instruments which were given twice before and after being given treatment. MANOVA test with SPSS version 24 was used as the data analysis of this study. The results showed that COVID-19 exercise with high and low intensity affected increasing aerobic capacity and mental toughness in adult men and women. However, there is a difference in the effect of highintensity and low-intensity COVID-19 exercise on increasing aerobic capacity and mental toughness in adult men and women. This study concluded that COVID-19 exercise with high intensity and low intensity both had a positive effect on increasing aerobic capacity and mental toughness in adult men
\end{abstract}

and women. However, low-intensity COVID-19 exercise has a better effect than high-intensity because it is considered safer for adults. The author suggests doing fun sports activities such as COVID-19 gymnastics to stay healthy physiologically and psychologically, especially during this pandemic.

Keywords - High Intensity, Low Intensity, COVID19 Gymnastics, Aerobic Capacity, Mental Toughness, Adult People

\section{INTRODUCTION}

The COVID-19 outbreak has spread throughout the world and made it a global pandemic that has made changes in the processes of human social life, including in Indonesia [1,2]. This change makes individuals need to readjust to various regulations implemented by the government to reduce the number of transmission and spread of this virus. One of the existing regulations requires individuals to stay at home doing all kinds of activities that are usually done outside the home, this is intended to avoid crowds and maintain distance which is one of the effective steps to prevent the transmission of this virus [3]. Especially for adults, being at home alone will certainly invite a lot of problems, both psychologically and physiologically. They will tend to be inactive or inactive because of the limitations 
of movement and socialization that can be done, as well as the duration of more screen time due to the demands of work during the COVID-19 pandemic, which in other words is a sedentary lifestyle [4].

Individuals become limited in doing activities so they often choose not to do activities. Individual inactivity causes various internal problems, such as fatigue and mental problems. For many individuals, the consequences of adversity negatively affect both physical and mental health and are often associated with impairments in social, educational, and occupational functioning [5]. A study conducted on approximately 10 million Google surveys regarding progress in the search for psychological health shortly after the stay-at-home or lockdown policy revealed that subjects were more likely to be characterized by tension, negative musings, restlessness, and self-destructive ideas developed significantly before lockdown [6]. The COVID-19 pandemic is also directly related to various psychological problems and sleep disorders in individuals [7]. This will be very dangerous if it continues to be ignored because it will have a long impact on a person's life, so appropriate steps are needed based on an analysis of the existing situation and conditions.

The above problems need to be addressed as soon as possible so that there will be no negative effects in the long term in human life, namely by having mental toughness and good aerobic capacity. Mental toughness is a general term that requires positive psychological resources, which is very important in various achievement contexts and the mental health domain [5]. Mentally tough individuals will have natural or developed psychological advantages that enable a person to be better at many things, in general, cope better than others with many demands and in particular, be more consistent and better than others at remaining determined, focused, confident, and in control under pressure [8]. In addition to mental toughness, adults also really need to have the good aerobic capacity, because it directly describes a person's level of fitness. If a person has a good level of fitness, then he will be able to do many things more optimally and avoid various problems, psychological and physiological [9]. This aerobic capacity can be measured by looking at the body's maximum ability to provide and consume oxygen ( $\mathrm{VO} 2 \mathrm{max}$ ) which is the product of maximum cardiac output ( $\mathrm{L}$ of blood $/ \mathrm{min})$ and the difference in arterial oxygen $(\mathrm{ml}$ $\mathrm{O} 2 / \mathrm{L}$ of blood) [10].

The author makes an exercise that aims to overcome this problem, namely COVID-19 gymnastics. This COVID-19 exercise provides manipulating the intensity in it (low-intensity and high-intensity) which can be used as a way to overcome the problems mentioned above. COVID19 exercise makes a person more active and receives various positive effects on the body [11-13]. This is a novelty because the author has not found a similar form of exercise that can be done specifically in situations and conditions like today. In addition, there are no studies that examine the effects of implementing this COVID-19 exercise. Thus, this study aims to examine COVID-19 exercise with low and high intensity on aerobic capacity and mental toughness in adults of different sexes. This is intended to get an accurate picture of how the effects occur specifically based on sex in adults.

\section{METHOD}

This study used an experimental method for 6 weeks (July-August 2021) using a pretest-posttest group design research design [14]. The subjects in this study were 150 subjects (65 male and 85 female adults) from various gymnastics clubs in Indonesia with the age of $31.4 \pm 2.729$ years. Subjects were selected using purposive sampling based on several considerations, namely age (25-40 years), marital status (married), and daily activities (dominated by activities at home). Subjects were then divided into two groups (low intensity and high-intensity group) consisting of 75 people each. The treatment given in the form of COVID-19 exercise is given for 6 weeks (July-August 2021) with a frequency of 3 sessions/week [15], which is given directly by a professional gymnastics expert. Each session consisted of 15 minutes of active movement and was repeated three times with a break of 2-3 minutes so that the total duration of active movement or treatment volume was 45 minutes with low to medium intensity (Figure 1). The research instruments used were The Walk Test [16] and Mental Toughness Inventory [8] which were given twice before and after being given treatment. The MANOVA test with SPSS version 24 was used as the data analysis of this study [17]. 


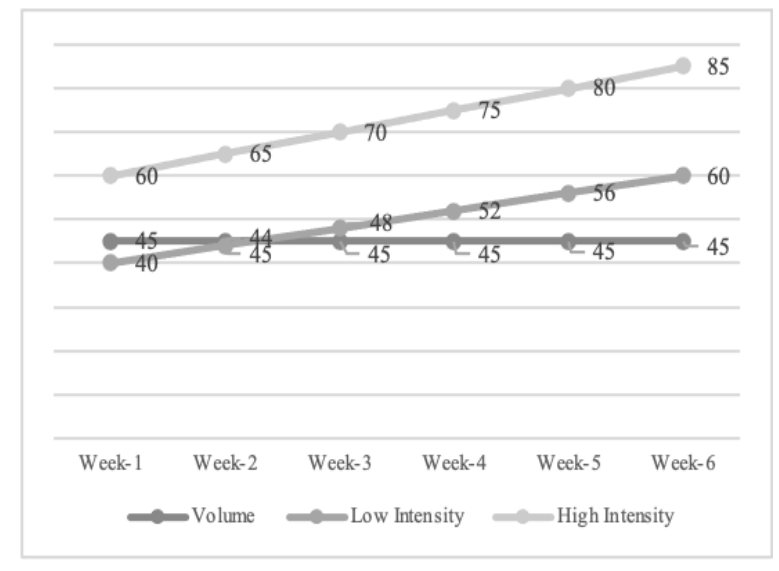

Figure 1. Volume and Intensity of COVID-19 Gymnastics

Figure 1 shows a graph of the volume and intensity of the COVID-19 exercise given during the treatment. It can be seen that the volume given every week is the same, which is 45 minutes, while the intensity given increases every week, starting from $40-60 \%$ for low intensity and $60-85 \%$ for high intensity. Determination of this intensity refers to sports performance guidelines for health [9].

\section{RESULT}

The author presents the results of data processing and analysis in the form of images, which can be seen in Figure 2.

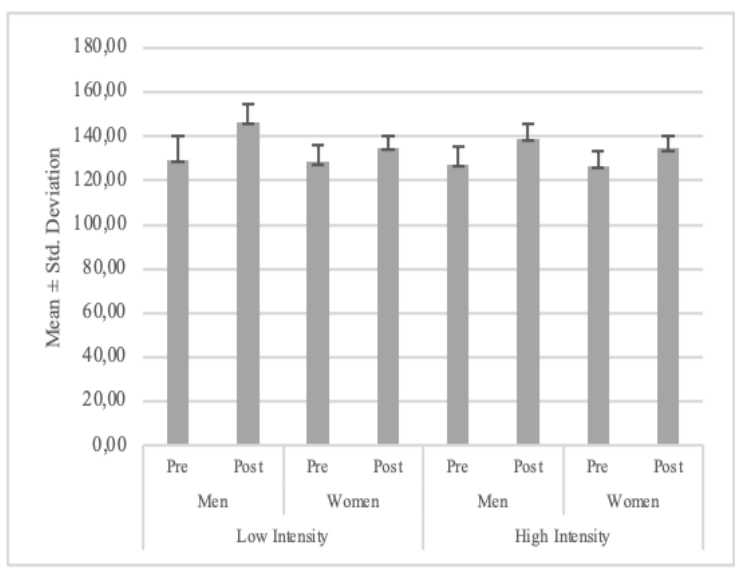

Figure 2. Error Bar of Mental Toughness

Figure 2 shows the mental toughness variable error bar by gender. It can be seen that there was an increase in the scores of the pre-test and post-test for both groups and gender. However, the low-intensity group (men $13.6 \%$ and women $6.4 \%$ ) had a higher percentage increase than the highintensity group (men 9.6\% and women 5.3\%). Although both groups experienced an increase, the low-intensity group gave a greater increase. This shows that low-intensity COVID-19 exercise is better than high-intensity in increasing mental toughness, both for adult men and women. Furthermore, the error bar of the aerobic capacity variable can be seen in Figure 3 .

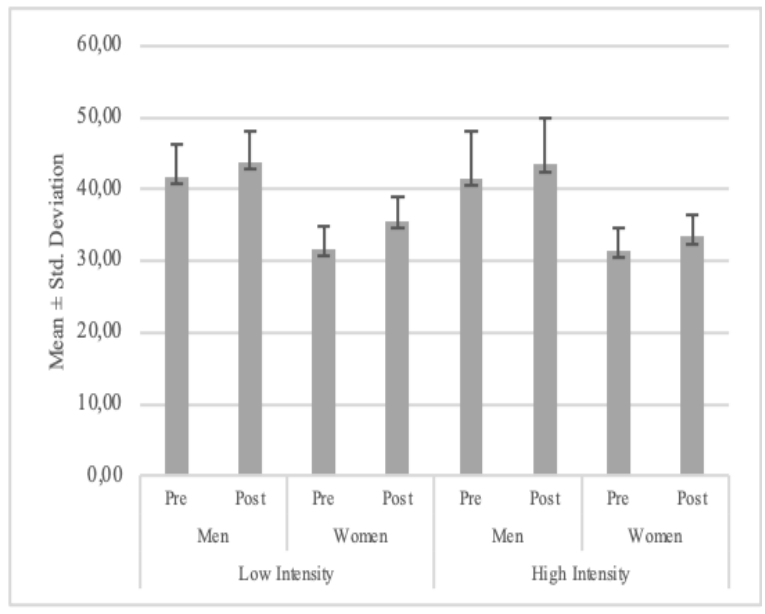

Figure 3. Error Bar of Aerobic Capacity

Figure 3 shows the error bar of the aerobic capacity variable by gender. It can be seen that there was an increase in the scores of the pre-test and post-test for both groups and gender. However, the low-intensity group (men $5.5 \%$ and women $12.4 \%$ ) had a higher percentage increase than the highintensity group (men $4.8 \%$ and women $6.4 \%$ ). Although both groups experienced an increase, the low-intensity group gave a greater increase. This shows that low-intensity COVID-19 exercise is better than high-intensity in increasing aerobic capacity, both for adult men and women. Next, the writer tested the hypothesis.

Before testing the hypothesis using MANOVA, the authors conducted a normality test and homogeneity test first as a prerequisite test. All data in this study were declared to be normally distributed, as well as the results of the homogeneity test which stated that all data were homogeneous. Based on the results of the MANOVA test, in the male sex, the Sig. $0.028<0.05$, it can be concluded that there is a significant effect of COVID-19 exercise with low and high intensity on mental toughness and aerobic capacity of male adults. 
While for the female sex, the Sig. $0.000<0.05$, it can be concluded that there is a significant effect of COVID-19 exercise with low and high intensity on mental toughness and aerobic capacity of female adults.

\section{DISCUSSION}

The existence of the COVID-19 pandemic will certainly make humans more careful in carrying out their activities, coupled with regulations made to suppress the transmission and spread of this virus. However, it's a shame if this is not handled wisely, because those who initially want to maintain their health will have a bad impact on health if they are not handled wisely, both psychologically and physiologically. The problem that exists shows that the COVID-19 pandemic has made a person less active and not exercising. This is due to several things, such as the number of tasks to be done, sports venues being closed, and so on. Like a previous study which stated that the majority of gym participants never used sterile wipes or products before or after using gym equipment $(61.6 \%)$, and $35.4 \%$ of gym staff did not use sterilizing materials distributed through fitness centers, and most of the fitness center participants had experienced an episode of skin infection or respiratory infection in the fitness center during the last 12 months $(22.2 \%)$, while $80.8 \%$ were not aware of the tinea microbe that causes athlete's foot, and $65.7 \%$ of them used bathing in the gym. gym after exercise [18].

There should be no reason not to exercise, exercise is very necessary for our body because a person's inactivity in physical activity will be very dangerous because it becomes one of the main modifiable risk factors worldwide and all deaths [19]. Regular participation in such activities is associated with a longer and better quality of life, reduced risk of various diseases, and many psychological and emotional benefits [20]. Studies suggest that sports participation is recommended as a form of leisure time for various age groups in an effort not only to improve physical health (such as the obesity crisis) but also to improve psychological and social health outcomes [21]. Therefore, the authors apply COVID-19 exercise as a solution to overcome this problem, namely by increasing the mental toughness and aerobic capacity of adults. The author tries to conduct a review based on gender differences to clarify the understanding of the benefits provided because there are differences in abilities between men and women [22-24].

In male adults, the results showed that the COVID-19 exercise given had a significant effect on the mental toughness and aerobic capacity of adults. The increase in the percentage of mental toughness occurred by $9.6 \%$ for high intensity and $13.6 \%$ for low intensity, while the increase in aerobic capacity occurred by $4.8 \%$ for high intensity and $5.5 \%$ for low intensity. This shows that low-intensity COVID-19 exercise is better than high-intensity exercise in male adults to improve mental toughness and aerobic capacity. The author sees that this is due to the age-appropriate intensity that tends to be less able to carry out high-intensity activities. However, the high-intensity COVID-19 exercise provided can still be done by adults because it is designed with movements that are not difficult.

In female adults, the results of the study showed the same thing as male adults, namely that there was a significant effect of COVID-19 exercise on the mental toughness and aerobic capacity of adults. However, the difference occurs in a large percentage which tends to be larger than male adults [25]. COVID-19 exercise with high intensity provides an increase in the percentage of mental toughness by $5.3 \%$, while high intensity by $6.4 \%$. While the increase in the percentage of aerobic capacity occurred by $6.4 \%$ for high intensity and $12.4 \%$ for low intensity. This result is quite interesting where previous studies suggest that high intensity provides a greater increase than low intensity [12]. These results are caused by the suitability of the intensity with age which may already tend to be less able to carry out high-intensity activities.

Exercising properly, correctly, measurably, and regularly is something that humans need. Studies suggest that if this is done optimally, there will be an increase in a person's physical fitness [13]. This COVID-19 exercise is an alternative solution for individuals (especially adults) to be more active in exercising, especially in situations and conditions like today. This COVID-19 exercise is designed in such a way that it is easy to do and still provides positive benefits. Studies suggest that aerobic exercise has been shown to have a positive effect on brain function and various components of physical ability [11]. Physical activity and exercise can reduce stress and anxiety, increase happiness levels, increase self-confidence, increase brain power, sharpen memory and increase muscle and bone strength, and help in preventing and reducing heart disease, obesity, fluctuations in blood sugar, cardiovascular disease, and cancer [26].

Adult individuals should be more aware of the importance of doing sports for their health and should not only focus on work with all its demands. If the adult individual is not strong enough to deal with these things psychologically, the conflict will 
likely occur, so it is very important for the individual to still have mental toughness [27]. Likewise with aerobic capacity, if an adult individual does not have a good aerobic capacity, then it is certain that he is not able to carry out activities optimally because he does not have a good level of physical fitness [9], as well as being an indicator of cardiovascular health, the higher the capacity aerobics a person, the higher the level of cardiovascular health, and vice versa $[10,12]$. Doing sports activities with gymnastics or others during a pandemic like this still has a positive effect on individuals $[28,29]$, so that the body is healthier and has a lower chance of being exposed to viruses.

\section{CONCLUSION}

This study concluded that high-intensity and low-intensity COVID-19 exercise both had a positive effect on increasing aerobic capacity and mental toughness in adult men and women. However, low-intensity COVID-19 exercise has a better effect than high-intensity because it is considered safer for adults. The author suggests doing fun sports activities such as COVID-19 gymnastics to stay healthy physiologically and psychologically, especially during this pandemic.

\section{ACKNOWLEDGMENT}

The author would like to thank the Ministry of Education, Culture, Research, and Technology of the Republic of Indonesia, as well as the Institute for Research and Community Service at the Universitas Pendidikan Indonesia for supporting the research and publication of this article.

\section{REFERENCES}

[1] Lai C-C, Shih T-P, Ko W-C, Tang H-J, Hsueh P-R. Severe acute respiratory syndrome coronavirus 2 (SARS-CoV-2) and coronavirus disease-2019 (COVID-19): The epidemic and the challenges. Int $\mathrm{J}$ Antimicrob Agents 2020;55:1-10. https://doi.org/https://doi.org/10.1016/j.ijant imicag.2020.105924.

[2] Fei Zhou, Yu T, Du R, Fan G, Liu Y, Liu Z, et al. Clinical Course And Risk Factors For Mortality Of Adult In Patients With COVID-19 In Wuhan, China: A Retrospective Cohort Study. J Med Study Res 2020;3:01-2 https://doi.org/10.24966/msr-5657/100015.
[3] Fauci AS, Lane HC, Redfield RR. Covid19 - Navigating the Uncharted. N Engl J Med 2020;382:1268-9. https://doi.org/10.1056/nejme2002387.

[4] Bute SS, Shete AN, Khan ST. A Comparative Study of VO2 Max in Young Female Athletes and Non-Athletes $\backslash n$. IOSR J Sport Phys Educ 2014;1:27-9.

[5] Lin Y, Mutz J, Clough PJ, Papageorgiou KA. Mental toughness and individual differences in learning, educational and work performance, psychological wellbeing, and personality: A systematic review. Front Psychol 2017;8:1-15. https://doi.org/10.3389/fpsyg.2017.01345.

[6] Jacobson NC, Lekkas D, Price G, Heinz M $\mathrm{V}$, Song M, O'Malley AJ, et al. Flattening the Mental Health Curve: COVID-19 Stayat-Home Orders Are Associated With Alterations in Mental Health Search Behavior in the United States. JMIR Ment Heal 2020;7. https://doi.org/10.2196/19347.

[7] Solehati T, Kosasih CE, Hermayanti Y, Mediani HS. The Psychological and SleepRelated Impact of Coronavirus Disease 2019 ( COVID-19 ): A Systematic Review 2021;16:65-74.

https://doi.org/10.21109/kesmas.v0i0.5037.

[8] Tibbert SJ. Mental toughness and overtraining behaviours 2013:1-371.

[9] Giriwijoyo HYSS. Fisiologi Kerja dan Olahraga. Pertama. Jakarta: PT. Raja Grafindo Persada; 2017.

[10] Magnan RE, Kwan BM, Ciccolo JT, Gurney B, Mermier CM, Bryan AD. Aerobic capacity testing with inactive individuals: The role of subjective experience. J Phys Act Heal 2013;10:2719. https://doi.org/10.1123/jpah.10.2.271.

[11] Irfannuddin, Fediani Y, Santoso B, Kadir MR, Dewi MR. The Recommended Aerobic Gymnastics Has Better Effects on Improving Cognitive and Motoric Ability in Children. Biosci Med 2018;2:35-44.

[12] Syamsudin F, Herawati L, Qurnianingsih E, Wungu CDK. HIIT for Improving Maximal Aerobic Capacity in Adults Sedentary Lifestyle. Hal Olahraga Nusant (Jurnal Ilmu Keolahragaan) 2021;4:1. 
https://doi.org/10.31851/hon.v4i1.5139.

[13] Jumareng H, Asmuddin, Maruka A, Saman A, Badaruddin, Setiawan E, et al. The effect of physical fitness gymnastics training 2012 on increasing of physical fitness. Hal Olahraga Nusant (Jurnal Ilmu Keolahragaan) 2021;4:216-25.

[14] Fraenkel JR, Wallen NE, Hyun HH. How to Design and Evaluate Research in Education. 8th Ed. New York: Mc Graw Hill; 2012.

[15] Bompa TO, Buzzichelli C. Periodization6th Edition: Theory and Methodology of Training. 2018. https://doi.org/10.1207/S15327051HCI152 3_6.

[16] California Deapartment of Education. Physical Fitness Test: Reference Guide. 2020.

[17] Santoso S. Complete Guide to Mastering Statistics with SPSS 24. Jakarta: Jakarta: PT. Elex Media Komputindo; 2017.

[18] Almasri D, Noor A, Diri R. Behavioral Changes in Gym Attending Due to COVID19 Pandemic: A Descriptive Survey. J Microsc Ultrastruct 2020;8:165-7. https://doi.org/10.4103/JMAU.JMAU_64_2 0 .

[19] Lavie CJ, Ozemek C, Carbone S, Katzmarzyk PT, Blair SN. Sedentary Behavior, Exercise, and Cardiovascular Health. Circ Res 2019;124:799-815. https://doi.org/10.1161/CIRCRESAHA.118 .312669.

[20] Bailey R, Wellard I, Dismore H. GIRLS' PARTICIPATION IN PHYSICAL ACTIVITIES AND SPORTS: BENEFITS, PATTERNS, INFLUENCES AND WAYS FORWARD. World Heal Organ n.d.:1-30.

[21] Eime RM, Young JA, Harvey JT, Charity MJ, Payne WR. A systematic review of the psychological and social benefits of participation in sport for adults: Informing development of a conceptual model of health through sport. Int J Behav Nutr Phys Act 2013;10. https://doi.org/10.1186/14795868-10-135.

[22] Cureton K, Bishop P, Hutchinson P, Newland H, Vickery S, Zwiren L. Sex difference in maximal oxygen uptake Effect of equating haemoglobin concentration. Eur J Appl Physiol Occup Physiol 1986;54:656-60. https://doi.org/10.1007/BF00943356.

[23] Sandbakk $\varnothing$, Ettema G, Leirdal S, Holmberg HC, Lacour JR. Gender differences in the physiological responses and kinematic behaviour of elite sprint cross-country skiers. Eur J Appl Physiol 2012;112:1087-94. https://doi.org/10.1007/s00421-011-2063-4.

[24] Saghiv MS, Sherve C, Sira D Ben, Saghiv M, Goldhammer E. Are there Differences between Adolescent Males and Females for Maintaining the Metabolic Cost at Maximal Oxygen Uptake? J Clin Exp Cardiolog 2017;08. https://doi.org/10.4172/21559880.1000519 .

[25] Hill DW, Smith JC. Aerobic Contribution Capacity: Role of aerobic contributin. Br J Sports Med 1993;27:45-8.

[26] Elmagd MA. Benefits, need and importance of daily exercise. $22 \sim$ Int $\mathbf{J}$ Phys Educ Sport Heal 2016;3:22-7.

[27] Middleton SC, Marsh HW, Martin AJ, Richards GE, Perry C. Developing the mental toughness inventory (MTI). Int Bienn SELF Res Conf 2005

[28] Kaur H, Singh T, Arya YK, Mittal S. Physical Fitness and Exercise During the COVID-19 Pandemic: A Qualitative Enquiry. Front Psychol 2020;11:1-10. https://doi.org/10.3389/fpsyg.2020.590172.

[29] Bobo-Arce M, Sierra-Palmeiro E, Fernández-Villarino MA, Fink H. Training in Rhythmic Gymnastics During the Pandemic. Front Psychol 2021;12:1-8. https://doi.org/10.3389/fpsyg.2021.658872. 